\title{
Confirmation of Linkage of the Loci for Myotonic Dystrophy and $\mathrm{ABH}$ Secretion
}

\author{
J. H. RENWICK,* SARAH E. BUNDEY, $\dagger$ M. A. FERGUSON-SMITH, $\ddagger$ and \\ MARIAN M. IZATT $\ddagger$
}

Mohr (1954) found hints that the locus of myotonic dystrophy belongs to the Secretor:Lutheran ( $S e: L u$ ) linkage group established by Mohr (1951). Despite their potential relevance for genetic counselling, these hints did not lead to further studies for reasons which may have revolved around the difficulties in phenotypic and genotypic categorization for the secretor and dystrophy loci. There may also have been some caution from an awareness of some limitations of the statistical procedures available at that time.

A reappraisal of the dystrophy linkage data by Renwick and Bolling (1971) arose from a routine Bayesian analysis of Mohr's data undertaken in 1968 as part of their comprehensive analysis of available linkage data. Using computer help, they assessed the linkage relationships between the three loci jointly and obtained the posterior probability that all were syntenic (on the same chromosome). This probability was 0.93 .

Plans were made to collect further data and were stimulated by two further developments. One was the revival of interest (Renwick, 1969) in the indirect technique of prenatal diagnosis using a linkage relationship (Edwards, 1956). The other was the improvement in methods for early recognition of heterozygotes for the dystrophy allele. A linkage study is here reported in which a re-investigation of many of the pedigrees that had been studied for that purpose by Bundey, Carter, and Soothill (1970) increases the probability that the three loci, $D m, S e$, $L u$, are on the same chromosome pair (syntenic). A preliminary report has already appeared (Renwick et al, 1971).

\section{Myotonic Dystrophy and the Pedigrees Studied}

These authors studied 34 pedigrees of myotonic

\footnotetext{
Received 8 June 1971.

* London School of Hygiene and Tropical Medicine, London WC1E 7HT. + MRC Clinical Genetics Unit, Institute of Child Health, and Institute of Neurology, London WCIN 1EH. ‡Institute of Genetics, University of Glasgow, Glasgow W2.
}

dystrophy with the aim of detecting, by special investigations, heterozygotes for the dystrophy allele before the age of clinical symptoms. (This age varies widely. Anamnestically and without diagnostic aid from clinical signs, it exceeds 35 years in about one third of the propositi of Lynas [1957] and also of Klein [1958].) Special tests performed on about half the clinically normal first-degree relatives showed that slit-lamp examination of the lens (through detection of characteristic multicoloured cortical opacities) and electromyography (through detection of electrical myotonia) could be used to identify heterozygotes before other clinical signs. It was considered that slit-lamp abnormalities were the earliest sign and could precede clinical manifestation by at least 6 years (Klein, 1958) and perhaps longer. The electromyogram could however be normal in the presence of lenticular opacities. A follow-up would be necessary to determine how far negative investigations in a clinically normal firstdegree relative would increase the probability that he or she was not a heterozygote.

Seventeen of the 34 pedigrees were chosen for linkage studies. Some of the pedigrees have been extended.* Charts of the pedigrees studied for linkage are given on pp. 411-414. The last two digits of the pedigree code names correspond to the family numbering of the 1970 study (Bundey $e t$ al, 1970), except for DM189 which corresponds to family 31. Clinical status and results of special investigations are reported in Bundey et al (1970).

Two additional families, DM135 and DM136, were not seen in the earlier study. In DM135 the proposita III.1 had been referred for genetic counselling; in DM136 the proposita IV.6 and her affected cousin IV.3 were seen at the Hospital for Sick Children.

\footnotetext{
* The detailed pedigrees of certain members of the families studied, in particular those who have been tested for blood group and other polymorphic markers, can be found in the Biological Data Collection of the General Library of the British Museum (Natural History), Cromwell Road, London SW7.
} 
DM189 had been investigated by $M$. d'A. Crawfurd, W. D. Fletcher, T. E. Cleghorn, E. B. Robson, and H. Harris (personal communication). A linkage study (including blood and secretor typing) had been carried out and some clinically normal relatives had undergone electromyography. Only a little further information on relatives was obtained in the present study.

The families were visited, the clinical status of each relative was verified, and blood and saliva samples were collected. A few relatives, not previously investigated, were examined by electromyography and for lenticular opacities with the Haag-Streit slit-lamp. The reason for these extra investigations was either a suspected change in clinical status or a query of a genetic counselling nature. Individuals scored as heterozygotes are those who, whatever their age, show clinical evidence of myotonic dystrophy or, who, while clinically normal, show unequivocal evidence of being heterozygous on slit-lamp or electromyographic examination. It was not possible to be certain about 'normal' individuals in view of the variation in the age of onset of signs. For the purposes of the linkage calculations, an individual has been scored as homozygous normal only if he or she shows no evidence of the dystrophy and has reached the age of 35 . There are 26 such individuals in the study and 13 have, additionally, undergone slit-lamp examination and/or electromyography with no findings indicating heterozygosity for the $D m$ allele.

All individuals who are under 35 years and have an affected or potentially affected parent have been excluded from the analysis unless they are clearly heterozygotes. When some or all are old enough to be scored for their $\mathrm{Dm}$ genotypes with greater reliability, their inclusion should improve the precision of the linkage estimates.

\section{Genetical Classification based on Clinical, Lenticular, and Myographic Findings}

Bundey et al (1970) have reported the clinical findings. Subsequently, in DM1B3, III.6 has developed clinical myotonia, which was not present at the original examination 2 years previously when he was 8 years of age. He also has characteristic lenticular opacities on slit-lamp examination. His brother, III.5, without clinical myotonia, has similar lenticular opacities; neither had previously been examined with the slit-lamp. In DM189, II.14 now aged 67, who had a normal electromyogram in 1964, now has typical lenticular opacities, but no clinical myotonia. In DM134, III.4 is clinically normal, has a normal electromyogram, but has characteristic lenticular opacities; she had not been seen previously. In DM189, I.3 aged 89 has senile cataracts, but no lenticular changes of the relevant type. In DM136, III.1 has a normal electromyogram.

There is no method for assessing accurately the extent of misclassification, particularly as the true segregation ratio may not be exactly 50:50 and as the mode of ascertainment is complex. However, it is considered that most if not all heterozygotes over 35 have been recognized. In the 19 families, among non-propositi with one affected parent, there were 111 aged 35 or over at the time of the study or at the time of death, and of these 56 were classed as affected, ie, $51 \%$. If the examination criteria for inclusion in this series had been as restrictive as those used in the classification for linkage purposes, the proportion affected would have been, if anything, greater than this. (This confidence in the classification of heterozygotes over 35 years is enhanced by consideration of the corresponding segregation ratio in those 18 pedigrees of the first study that were not included in the second: 10 affected persons out of 20.)

\section{Polymorphic Marker Loci}

A wide range of polymorphic loci controlling erythrocyte antigens, serum proteins, cell enzymes are being tested.* Most of the methods used are based on those of Race and Sanger (1968) and on Giblett's modifications (1969) of techniques from London and elsewhere.

The Secretor Locus and its alleles $S e$ and se. On an erythrocyte or other human cell, the A, B, or $\mathrm{H}$ antigen is present as a glycosphingolipid. In genotypes having at least one $\mathrm{Se}$ allele, some of the same antigenic specificity is also built up by the $\mathrm{ABH}$ enzyme system as a glycoprotein. This is water-soluble and secreted in saliva and other body fluids including the amniotic fluid. Another substrate of the ABH enzyme system, in the presence of an $S e$ allele, is Le antigen which is converted to Le ${ }^{b}$. The $\operatorname{Le}(\mathrm{a}-)$ phenotype thus indicates presence of at least one $\mathrm{Se}$ allele unless there is some block in the synthesis of $\mathrm{Le}^{\mathrm{a}}$ substance itself. Such a block occurs in homozygotes for the $l$ allele at the true Lewis locus. In most European populations the frequency of such homozygotes is about $4 \%$. Even of these, only about $23 \%$ of the genotypes will be

* The results to date are available from the Biological Data Collection of the General Library of the British Museum (Natural
History). 
misclassified as containing at least one $S e$ allele because, in the remaining $77 \%$, the genotype will be correctly deduced to be a secreting one. Thus in a sample such as that of Mohr (1954) only $1 \%$ error $(23 \%$ of $4 \%)$ is expected when the genotype is scored from the Le(a) phenotype. The elucidation of these interactions is largely the work of Grubb (1951), Ceppellini (1955), Kabat (1956), Morgan and Watkins (1969), and Watkins (1971).

The secretor locus has been satisfactorily scored on the saliva in the present study and the detectability of $\mathrm{Le}^{\mathrm{a}}$ on erythrocytes was to be used only to confirm the absence of the $\mathrm{Se}$ allele. However owing to the poor quality of the only anti-Le ${ }^{\mathrm{a}}$ sera available except those for DM189, the confirmatory Le(a) typing of the erythrocytes was not sufficiently reliable and is not recorded.

Mohr's Data on Myotonic Dystrophy. The pedigrees of Thomasen (1948) were tested for various blood group markers by Mohr (1954). The results from testing Lewis will be described in terms of the $S e$ locus in the light of the present-day interpretations of their interactions.

Mohr detected indications of linkage of the dystrophy locus with the $S e$ locus and with the $L u$ locus but, as noted above, these were not followed up. The standard error of the sib-pair linkage statistic had just been shown by Smith (1953) to be underestimated. The relationship between Lewis and Secretor had not been clarified. Another factor contributing to the lack of conviction or follow-up was the difficulty in genotyping those phenotypically unaffected by the disease. This difficulty arises from the variation in the age of onset.

A recent re-analysis of these dystrophy data by Renwick and Bolling (1970 and 1971), that involves the three loci simultaneously, yields a posterior probability of 0.93 that they are syntenic. The diagnoses made by Thomasen (1948), sometimes with assistance from slit-lamp microscopy, were used without modification whatever the person's age. A re-examination of those persons classed as normal, followed by a repeat of the analysis, may well improve the dependability of the linkage estimates, particularly as some of those persons were under 35 years at the time of examination.

\section{Linkage Analysis}

The analysis follows that given by Renwick and Bolling (1971) for Mohr's data but the complication of non-independence of the linkage observations on the three intervals such as that allowed for in DM1.4 of those data did not arise in the present data. For convenience, the lods calculated with computer aid on Mohr's data (and the adjustment required for the non-independence mentioned above) are given here, pedigree by pedigree, together with those of the present series. The lods are given for a range of values of $\theta$, where $\theta$ represents both the male and female recombination fractions. The implications of a sex difference in $\theta$ are discussed by Renwick and Bolling (1971).

In Table I, the lods relate to the established $L u: S e$ linkage (Mohr, 1951). They are based partly on our own data but mainly on pedigree data that have been kindly made available from a large number of laboratories notably those of Drs Mohr, Race, Greenwalt, Cleghorn, Harris, Lawler, and Lamm. For reasons of comparability, these lods were used for both analyses-that of Mohr's data alone and that of the combined data.

In Table II, the lods relate to the $D m$ : Se interval. It may be noted that in neither series is there clear evidence of even a single recombination in this interval.

In Table III, the lods relate to the $D m: L u$ interval. The present series adds practically nothing here, but even on simple inspection of the lods from Mohr's data, an ordering of the loci that makes this the longest interval of the three is seen to be favoured.

\section{TABLE I}

AGGREGATE LODS FROM NUMEROUS PEDIGREES, PUBLISHED AND UNPUBLISHED, FOR $S e: L u$ INTERVAL

\begin{tabular}{|c|c|c|c|c|c|c|c|c|c|c|c|}
\hline & \multicolumn{11}{|c|}{ Recombination Fraction $(\theta)$} \\
\hline & 0.5 & 0.45 & 0.40 & 0.35 & $0 \cdot 30$ & 0.25 & $0 \cdot 20$ & $0 \cdot 15$ & $0 \cdot 10$ & 0.05 & 0 \\
\hline $\begin{array}{l}\text { Lods ( } S e: L u \text { ) } \\
\text { Adjustment (c) }\end{array}$ & $\begin{array}{l}0 \\
0 \\
\end{array}$ & $\begin{array}{r}1.107 \\
-0.004 \\
\end{array}$ & $\begin{array}{r}3.765 \\
-0.016 \\
\end{array}$ & $\begin{array}{r}7.219 \\
-0.035 \\
\end{array}$ & $\begin{array}{r}10.858 \\
-0.057 \\
\end{array}$ & $\begin{array}{r}14.234 \\
-0.081 \\
\end{array}$ & $\begin{array}{r}16.806 \\
-0.106 \\
\end{array}$ & $\begin{array}{r}18.428 \\
-0.131 \\
\end{array}$ & $\begin{array}{r}17.938 \\
-0.155\end{array}$ & $\begin{array}{r}12.736 \\
-0.178 \\
\end{array}$ & $\begin{array}{l}-\infty \\
-0.201\end{array}$ \\
\hline Adjusted lods & 0 & $1 \cdot 103$ & $3 \cdot 749$ & $7 \cdot 184$ & $10 \cdot 810$ & $14 \cdot 153$ & $16 \cdot 700$ & $18 \cdot 297$ & $17 \cdot 783$ & 12.558 & $-\infty$ \\
\hline
\end{tabular}

The lods include data from the laboratories of Drs Mohr, Race, Greenwalt, Cleghorn, Harris, Lawler, Renwick, and several others. They are given for a range of values of the recombination fraction, $\theta$, without regard to the known difference between the male and fermale values. The adjustment, $c$, which is occasioned by the non-independence in DM1.4 of the data on the three intervals is also shown (see text). 
TABLE II

LODS FROM PEDIGREES OF MOHR (1954) AND PEDIGREES OF PRESENT SERIES FOR $D m: S e$ INTERVAL

\begin{tabular}{|c|c|c|c|c|c|c|c|c|}
\hline \multicolumn{2}{|c|}{ Pedigree } & \multicolumn{7}{|c|}{ Recombination Fraction $(\theta)$} \\
\hline Mohr (1954) & Code Name* & 0.5 & 0.4 & 0.3 & 0.2 & 0.1 & 0.05 & 0 \\
\hline 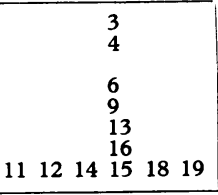 & $\begin{array}{l}\text { DM1.3 } \\
\text { DM1.4 } \\
\text { Adjustment }(c) \\
\text { DM1.6 } \\
\text { DM1.9 } \\
\text { DM113 } \\
\text { DM116M }\end{array}$ & $\begin{array}{l}0 \\
0 \\
0 \\
0 \\
0 \\
0 \\
0 \\
0\end{array}$ & $\begin{array}{r}-0.006 \\
0.038 \\
-0.016 \\
0.044 \\
0.024 \\
-0.016 \\
0.147 \\
0.003\end{array}$ & $\begin{array}{r}-0.025 \\
0.152 \\
-0.057 \\
0.146 \\
0.090 \\
-0.067 \\
0.428 \\
0.012\end{array}$ & $\begin{array}{r}-0.059 \\
0.312 \\
-0.106 \\
0.252 \\
0.181 \\
-0.153 \\
0.702 \\
0.022\end{array}$ & $\begin{array}{r}-0.111 \\
0.492 \\
-0.155 \\
0.282 \\
0.277 \\
-0.280 \\
0.943 \\
0.023\end{array}$ & $\begin{array}{r}-0.146 \\
0.584 \\
-0.178 \\
0.195 \\
0.324 \\
-0.358 \\
1.052 \\
0.017\end{array}$ & $\begin{array}{r}-0.188 \\
0.675 \\
-0.201 \\
-0.240 \\
0.371 \\
-0.444 \\
1.153 \\
0.005\end{array}$ \\
\hline \multicolumn{2}{|c|}{ Total lods (Mohr's study) } & $\mathbf{0}$ & 0.218 & 0.679 & $1 \cdot 151$ & 1.471 & 1.490 & 1.131 \\
\hline $\begin{array}{llllll}8 & 16 & 20 & 21 & 22 & 36\end{array}$ & $\begin{array}{l}\text { DM1B1 } \\
\text { DM1B2 } \\
\text { DM1B3 } \\
\text { DM1B7 } \\
\text { DM1B9 } \\
\text { DM110 } \\
\text { DM127 } \\
\text { DM132 } \\
\text { DM134 } \\
\text { DM189 }\end{array}$ & $\begin{array}{l}0 \\
0 \\
0 \\
0 \\
0 \\
0 \\
0 \\
0 \\
0 \\
0 \\
0\end{array}$ & $\begin{array}{r}0.026 \\
0.006 \\
0.006 \\
0.012 \\
0.025 \\
0.014 \\
-0.015 \\
-0.014 \\
-0.022 \\
-0.012 \\
0.002\end{array}$ & $\begin{array}{r}0.096 \\
0.024 \\
0.026 \\
0.031 \\
0.096 \\
0.064 \\
-0.017 \\
-0.058 \\
-0.047 \\
-0.040 \\
0.006\end{array}$ & $\begin{array}{r}0.192 \\
0.052 \\
0.056 \\
0.063 \\
0.199 \\
0.153 \\
0.025 \\
-0.144 \\
-0.079 \\
-0.077 \\
0.012\end{array}$ & $\begin{array}{r}0.299 \\
0.088 \\
0.096 \\
0.112 \\
0.320 \\
0.273 \\
0.109 \\
-0.312 \\
-0.120 \\
-0.113 \\
0.009\end{array}$ & $\begin{array}{r}0.353 \\
0.109 \\
0.119 \\
0.144 \\
0.384 \\
0.341 \\
0.156 \\
-0.465 \\
-0.146 \\
-0.124 \\
0.008\end{array}$ & $\begin{array}{r}0.407 \\
0.131 \\
0.143 \\
0.181 \\
0.448 \\
0.414 \\
0.200 \\
-0.760 \\
-0.177 \\
-0.125 \\
0.008\end{array}$ \\
\hline \multicolumn{2}{|c|}{ Total lods (present study) } & 0 & 0.028 & 0.181 & 0.452 & 0.761 & 0.879 & 0.870 \\
\hline \multicolumn{2}{|c|}{ Lods (grand total) } & 0 & 0.246 & 0.860 & 1.603 & $2 \cdot 232$ & 2.369 & 2.001 \\
\hline
\end{tabular}

The lods are given for a range of values of the recombination fraction, $\theta$. The adjustment, $c$, of the lods for DM1.4 is to allow for the non-independence of the data on the three intervals. In DM132, II.6 is not yet included in the calculation. DM 135 is uninformative.

* All the pedigrees in the second half of the Table are those of the present paper.

TABLE III

LODS FROM MOHR'S PEDIGREES (1954) AND PEDIGREES OF PRESENT SERIES FOR Dm:Lu INTERVAL

\begin{tabular}{|c|c|c|c|c|c|c|c|c|}
\hline \multicolumn{2}{|c|}{ Pedigree } & \multicolumn{7}{|c|}{ Recombination Fraction $(\theta)$} \\
\hline Mohr (1954) & Code Name & 0.5 & 0.4 & 0.3 & 0.2 & 0.1 & 0.05 & 0 \\
\hline $\begin{array}{lllllll} & & & 4 & & \\
& & & & & \\
& & 12 & & \\
& & & 15 & & & \\
& & & 19 & & & \\
3 & 6 & 7 & 11 & 13 & 14 & 18\end{array}$ & $\begin{array}{l}\text { DM1.4 } \\
\text { Adjustment }(c) \\
\text { DM112 } \\
\text { DM115 } \\
\text { DM119 }\end{array}$ & $\begin{array}{l}0 \\
0 \\
0 \\
0 \\
0 \\
0\end{array}$ & $\begin{array}{r}0.255 \\
-0.016 \\
-0.009 \\
0.457 \\
0.009 \\
-0.001\end{array}$ & $\begin{array}{r}0.612 \\
-0.057 \\
-0.035 \\
0.800 \\
0.033 \\
-0.002\end{array}$ & $\begin{array}{r}0.894 \\
-0.106 \\
-0.084 \\
1.030 \\
0.071 \\
-0.004\end{array}$ & $\begin{array}{r}0.946 \\
-0.155 \\
-0.162 \\
1.086 \\
0.120 \\
-0.006\end{array}$ & $\begin{array}{r}0.747 \\
-0.178 \\
-0.218 \\
0.949 \\
0.146 \\
-0.006\end{array}$ & $\begin{array}{l}-\infty \\
-0.201 \\
-0.289 \\
-\infty \\
0.174 \\
-0.007\end{array}$ \\
\hline \multicolumn{2}{|c|}{ Total lods (Mohr's study) } & $\mathbf{0}$ & 0.695 & 1.351 & 1.801 & 1.829 & 1.440 & $-\infty$ \\
\hline \multicolumn{2}{|c|}{ Total lods (present study)* } & 0 & 0.001 & 0.002 & 0.005 & 0.009 & 0.012 & 0.015 \\
\hline \multicolumn{2}{|c|}{ Lods (grand total) } & 0 & 0.696 & 1.353 & 1.806 & 1.838 & 1.452 & $-\infty$ \\
\hline
\end{tabular}

The lods are given for a range of values of the recombination fraction, $\theta$. The present series contributes only negligibly to these lods. The adjustment, $c$, of the lods for DM1.4 is to allow for the non-independence of the data on the three intervals.

* See Table II for pedigree names.
data on the three intervals.

This is confirmed by the analysis summary presented in Table III which incorporates all available data from the two series. The odds on synteny of all three loci are seen to be $92: 1$ (ie, the probability is 0.99 ).

The three-locus computer analysis also gives us three distributions (for example of the Dm: Se map-length). Each is conditional on a particular ordering but since the distributions are unnormed, we have been able to combine them simply by addition to obtain an overall distribution. This has a peak in the region of $0.04 \mathrm{M}(\theta=0.04)$. From the graph, we have found the narrowest $95 \%$ probability zone by trial and error usage of a planimeter: 


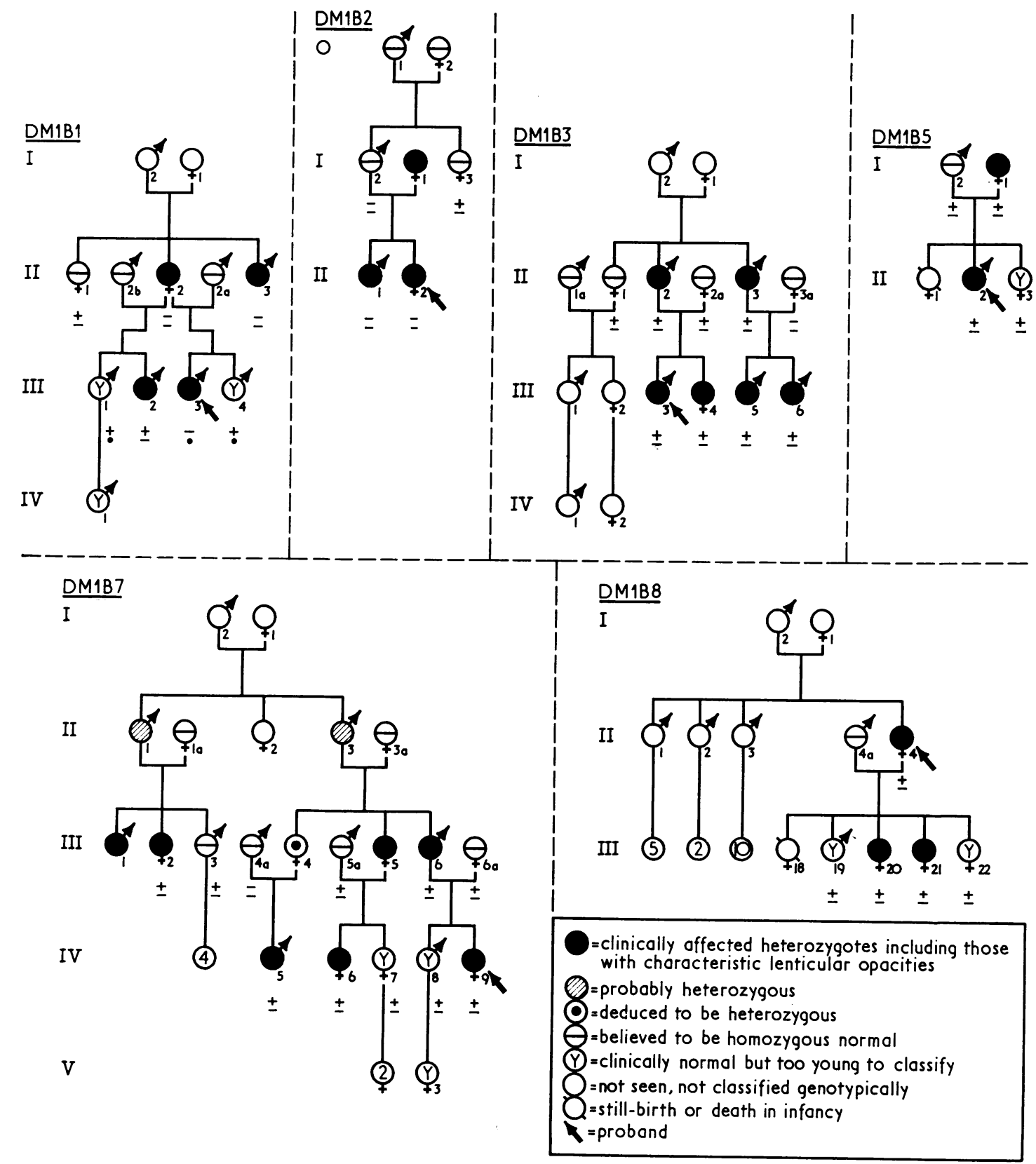

Charts of the pedigrees studied for linkage are given in this and the following three pages. The secretor phenotype $(+$ or -$)$ is indicated under the number or the symbol of each tested individual and the Lu(a) phenotype is indicated below this. A dot indicates not
tested. 


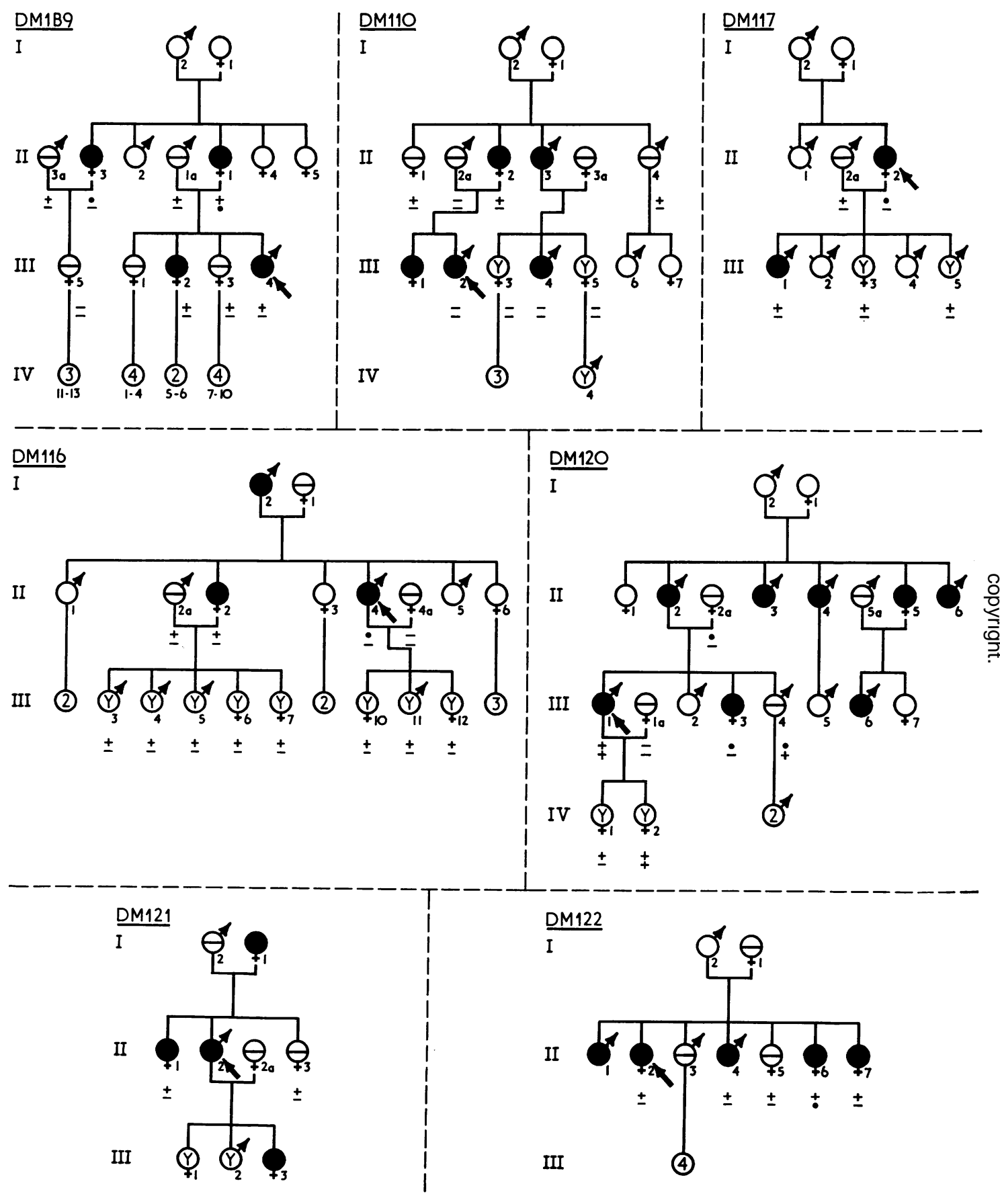



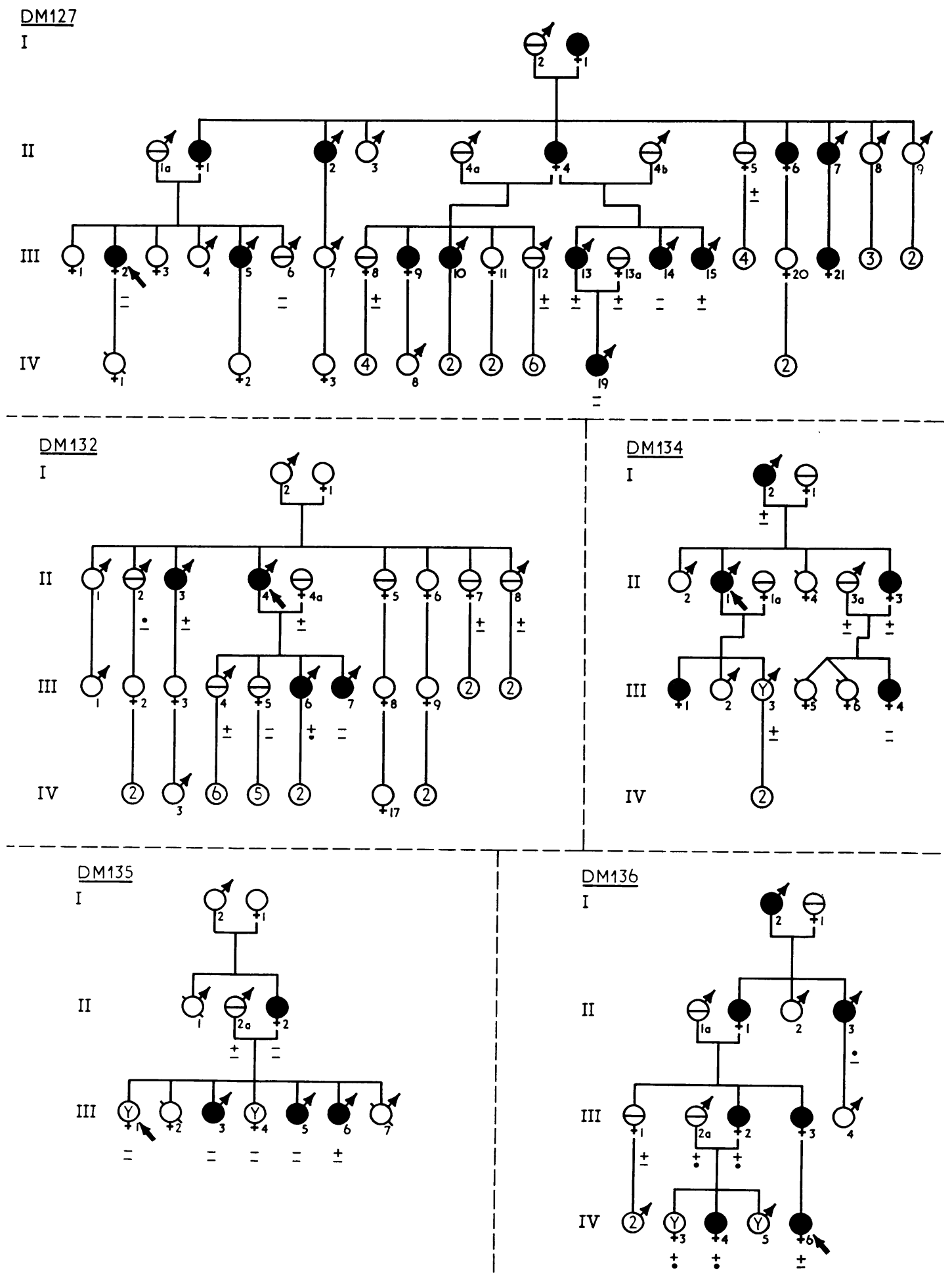


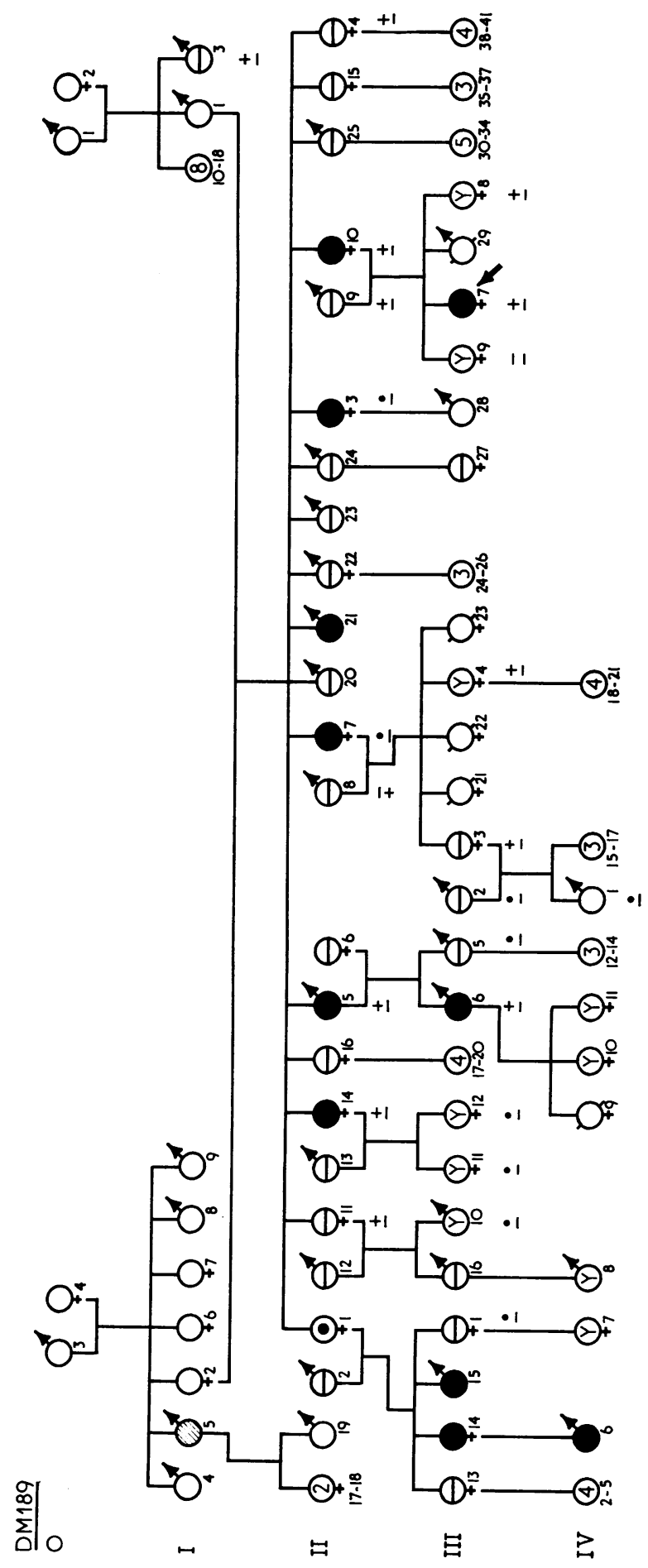


it extends from 0 to 0.21 morgans and corresponds to the region $0 \leqslant \theta \leqslant 0 \cdot 21$.

For counselling purposes we may require the probability that a particular child is a recombinant. Renwick and Bolling (1971) explain why this probability turns out to be higher than the maximum probability estimate of $\theta$. It is about 0.073 -almost $2 \hat{\theta}$ in this instance.

\section{Clinical Significance}

This is the first inherited disorder with onset in adult life, where linkage to autosomal marker loci has been found. One clinical application of such linkage will be in genetic counselling. The most valuable information can be offered in a family where the affected parent is a secretor, married to a non-secretor, and the coupling phase is known as a result of studies on other relatives. If, in this affected parent, the $\mathrm{Dm}$ allele is on the same homologue as the $S e$ allele, and the clinically normal offspring is secretor negative, there would be a $100 \%$ confident prediction of normality for that offspring, but for the possibility of genetic recombination. As explained by Renwick and Bolling (1971) the prediction still has a $92 \%$ probability of being correct even when allowance is made for recombination. If on the other hand, the offspring in such a family is secretor positive, then there is a good chance that he or she has inherited the $\mathrm{Dm}$ allele along with the $\mathrm{Se}$ allele. If, in the future, the homozygous secretor state can be distinguished from the heterozygous state, then linkage information will be helpful in a larger proportion of families.

The secretor status of the embryo may be recognized even at 9 weeks' gestation, by detection of antigens in the amniotic fluid (Harper and Hutchinson, 1970) so there may be occasions when, using similar arguments, we may assess the probability that the fetus of an affected individual has the $D m$ allele. In a small proportion of affected $\times$ normal matings, prenatal testing of embryonic secretor status may be useful. The parents then have the option of choosing abortion if the risk of transmission is high, in the knowledge that in a subsequent pregnancy similar tests could indicate a much smaller risk. No limitations of family size need, therefore, be involved. There are no suitable pregnancies at present in the families of the present study.

\section{Summary}

Close linkage of the autosomal loci, $\mathrm{Dm}, \mathrm{Se}, \mathrm{Lu}$ (for myotonic dystrophy, ABH secretion, and the Lutheran blood group respectively), which was adumbrated by Mohr (1954), has been established. Criteria for classification of the $\mathrm{Dm}$ and Se phenotypes in the study of a score of informative pedigrees are discussed with emphasis on slit-lamp microscopy and electromyography. Some important implications of the $D m: S e$ linkage for genetic counselling, particularly prenatally, are set out.

We are grateful to the consultants of the National Hospital for Nervous Diseases and the Hospital for Sick Children for permission to study the families of patients under their care. We thank Dr A. D. Stoker and Dr D. Smith for help with visiting members of DM135 and DM120 respectively.

The computing work was made possible by a grant from the John A. Hartford Foundation, by grant GM-10189 from the US National Institutes of Health to Dr V. A. McKusick, and by the services and facilities of the Homewood and Medical Computing Centers of Johns Hopkins University and its Medical Institutions. These are partly supported by educational contributions from the International Business Machines Corporation, and by a grant FR-00004 from the US National Institutes of Health. The data processing was supported in part by grants G960/109B and G968/206B and some of the laboratory work by G969/52B from the Medical Research Council (UK). Much of the laboratory work was supported by a grant from the Scottish Hospital Endowment Research Trust to Dr M. A. Ferguson-Smith. The technical assistance of Mrs J. Black, Mrs F. MacColl, Miss J. van den Branden, Miss S. Richards, and Miss L. Barron with particular polymorphic systems is appreciated. Mrs L. Maudling and Miss II. M. Wancowicz assisted in the data processing.

We are grateful to Dr C. O. Carter for his advice and comments during this study.

\section{REFERENCES}

Bundey, S., Carter, C. O., and Soothill, J. F. (1970). Early recognition of heterozygotes for the gene for dystrophia myotonica. fournal of Neurology, Neurosurgery and Psychiatry, 33, 279-293.

Ceppellini, R. (1955). On the genetics of secretor and Lewis characters: a family study. In Proceedings of the 5th Congress of the International Society of Blood Transfusion, Paris, pp. 207-211.

Edwards, J. H. (1956). Antenatal detection of hereditary disorders. Lancet, 1, 579.

Giblett, E. R. (1969). Genetic Markers in Human Blood. Blackwell, Oxford.

Grubb, R. (1951). Observations on the human blood group system Lewis. Acta Pathologica et Microbiologica Scandinavica, 28, 6181.

Harper, P. and Hutchinson, J. R. (1970). ABO secretor status of the fetus in early pregnancy - a genetic marker identifiable by amniocentesis. (Abstr.) American fournal of Human Genetics, 22, $41 \mathrm{a}-42 \mathrm{a}$.

Kabat, E. A. (1956). Blood Group Substances: Their Chemistry and Immunochemistry. Academic Press, New York.

Klein, D. (1958). La dystrophie myotonique (Steinert) et la myotonie congénitale (Thomsen) en Suisse. Fournal de Génétique Humaine, Suppl., 7, 1-328.

Lynas, M. A. (1957). Dystrophia myotonica with special reference to Northern Ireland. Annals of Human Genetics, 21, 318-351.

Mohr, J. (1951). Estimation of linkage between the Lutheran and the Lewis blood groups. Acta Pathologica et Microbiologica Scandincvica, 29, 339-344.

Mohr, J. (1954). A study of linkage in man. Opera ex Domo Biologiae Hereditariae Humanae Universitatis Hafniensis, Vol. 33. Munksgaard, Copenhagen. 
Morgan, W. T. J. and Watkins, W. M. (1969). Genetic and biochemical aspects of human blood group $\mathrm{A}-, \mathrm{B}-, \mathrm{H}-, \mathrm{Le}^{\mathrm{a}-}$, Le $^{\text {b }}$ - specificity. British Medical Bulletin, 25, 30-34.

Race, R. R. and Sanger, R. (1968). Blood Groups in Man, 5 th ed. Blackwell, Oxford.

Renwick, J. H. (1969). Widening the scope of antenatal diagnosis. Lancet, 2, 386.

Renwick, J. H. and Bolling, D. R. (1970). The linkage method of assignment of loci to individual autosomes. (Abstr.). Heredity, $25,150$.

Renwick, J. H. and Bolling, D. R. (1971). An analysis procedure illustrated on a triple linkage of use for prenatal diagnosis of myotonic dystrophy. Fournal of Medical Genetics, 8, 399-406.
Renwick, J. H., Bundey, S. E., Ferguson-Smith, M. A., and Izatt, M. M. (1971). Mohr's linkage hat-trick confirmed: enables prenatal diagnosis of myotonic dystrophy from secretor phenotype of fetus. (Abstr.) Excerpta Medica, International Congress Series, 233, 150.

Smith, C. A. B. (1953). The detection of linkage in human genetics. fournal of the Royal Statistical Society, 2, 153-192. Series B.

Thomasen, E. (1948). Myotonia. Thomasen's disease. Paramyotonia. Dystrophia myotonica. Opera ex Domo Biologiae Hereditariae Humanae Universitatis Hafniensis, Vol. 17. Munksgaard, Copenhagen.

Watkins, W. M. (1971). In Glycoproteins, 2nd ed., ed. A. Gottschalk, Chapter 10. Elsevier, Amsterdam. 